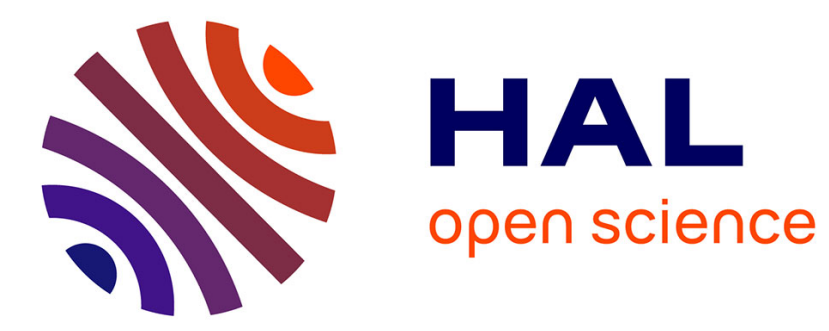

\title{
Monitoring of distributed defects on HSM spindle bearings
}

Côme de Castelbajac, Mathieu Ritou, Laporte Sylvain, Benoît Furet

\section{To cite this version:}

Côme de Castelbajac, Mathieu Ritou, Laporte Sylvain, Benoit Furet. Monitoring of distributed defects on HSM spindle bearings. Applied Acoustics, 2014, 77, pp.159-168. 10.1016/j.apacoust.2013.07.008 . hal-00852246

\section{HAL Id: hal-00852246 https://hal.science/hal-00852246}

Submitted on 22 Aug 2013

HAL is a multi-disciplinary open access archive for the deposit and dissemination of scientific research documents, whether they are published or not. The documents may come from teaching and research institutions in France or abroad, or from public or private research centers.
L'archive ouverte pluridisciplinaire HAL, est destinée au dépôt et à la diffusion de documents scientifiques de niveau recherche, publiés ou non, émanant des établissements d'enseignement et de recherche français ou étrangers, des laboratoires publics ou privés. 


\title{
Monitoring of distributed defects on HSM spindle bearings
}

\author{
C. de Castelbajac ${ }^{*, a, b}$, M. Ritou ${ }^{a}$, S. Laporte ${ }^{b}$, B. Furet ${ }^{a}$ \\ ${ }^{a} I R C C y N$ (UMR CNRS 6597 - Institut de Recherche en Communications et Cybernétique de Nantes), \\ Université de Nantes, 1 quai de Tourville, 44035 Nantes, France. \\ ${ }^{\mathrm{b}}$ MITIS SAS, 12 rue Johannes Gutenberg, 44340 Bouguenais, France \\ * Corresponding author. E-mail: cdecastelbajac@mitis.fr \\ Tel.: +33 2405924 21; Fax: + 332405947 85;
}

\begin{abstract}
The High Speed Machining (HSM) spindle is one of the most critical bearing applications, because it requires both high speed and high power in order to obtain high quality and productivity. Therefore, bearing condition monitoring is important. Firstly, this paper presents a real and typical spindle life example. The vibration signals and their evolution are discussed in relation to the bearing failures that have been observed after the spindle disassembly. Cleavage notably occurred on the ceramic balls of the hybrid ball bearing. Damaged balls and their chippings then damageduniformly the rings raceways on the whole circumference. As a consequence, a noise component increasesin vibration signal due to the worsening ofthe ball-race contact during the rolling process.In a second section, the noise component produced by bearing condition is studied and characterized. The frequency spectrum distribution is briefly discussed in relation to a signal model.It is demonstrated by Pearson's test that the distribution follows a Gaussian lawall along the spindle life. Besides, it evolves with bearing condition. Thus, a new criterion, called SBN (Spindle Bearing Noise), is proposed for the monitoring of the uniformly distributed defect. A specific monitoring device was also developed in order to collect real industrial data during the spindle lifetime.Vibration signalsare used in order to evaluate the criterion relevancy by comparison with the current best practices. The analyses through three required conditions for bearing condition monitoring and based on three spindles signals, have shown some good results.
\end{abstract}

Keywords: high speed spindle, bearing condition monitoring, distributed defects, noise. 


\begin{tabular}{|c|c|}
\hline \multicolumn{2}{|c|}{ Nomenclature } \\
\hline$\alpha$ & Contact angle of bearing \\
\hline$\Delta T_{a c q}$ & Acquisition time \\
\hline$\mu_{p}$ & Pearson test \\
\hline$A_{R M S}$ & Root Mean Square Acceleration \\
\hline$B P F I$ & Ball Pass Frequency of the Inner Race \\
\hline$B P F O$ & Ball Pass Frequency of the Outer Race \\
\hline$B S F$ & Ball Spin Frequency \\
\hline$D_{b}$ & Diameter of the bearing balls \\
\hline$D_{m}$ & Mean diameter of the bearing \\
\hline$d m \cdot N$ & product of bearing mean diameter (mm) and shaft speed (rpm) \\
\hline$F_{b}(k)$ & Contribution of primary and secondary bearing-induced frequencies \\
\hline$F_{c}(k)$ & Contribution of cutting frequencies (tooth-passing and/or chatter frequencies) \\
\hline$F_{e}(k)$ & Contribution of electromagnetic interferences \\
\hline$f_{\text {ech }}$ & Sampling frequency \\
\hline$F_{n}(k)$ & Contribution of other mechanical components of the spindle and/or the machine-tool \\
\hline$f_{r}$ & Shaft frequency \\
\hline$F_{s}(k)$ & Contribution of the shaft frequencies \\
\hline FTF & Fundamental Train Frequency \\
\hline$H S M$ & High Speed Machining \\
\hline$j$ & Harmonic order \\
\hline MTTF & Mean Time To Failure \\
\hline$N_{b}$ & Number of bearing balls \\
\hline$R_{b}(k)$ & Contribution of the noise producted by the bearing condition \\
\hline$R_{m}(k)$ & Contribution of the measuring noise \\
\hline$S B N_{0}$ & Spindle Bearing Noise for an unused bearing \\
\hline$S B N$ & Spindle Bearing Noise \\
\hline$V_{R M S}$ & Root Mean Square Velocity \\
\hline$X(k)$ & Frequency-domain vibration signal recorded on a bearing \\
\hline $\bar{X}$ & Mean of $X(k)$ \\
\hline$Z$ & Number of teeth of a cutting tool \\
\hline
\end{tabular}




\section{Introduction}

The High Speed Machining (HSM) requires high speed and high power spindles to obtain high quality and productivity. One of the most critical applications for the spindle concerns the manufacturingof aeronautical structural parts made of aluminum alloy. Indeed, high material removal ratesrequiredduring the long rough milling operations, leading to high power and force transmitted to the spindle bearing. Besides, very high cutting speed, i.e. shaft speed,is used(contrary to hard to cut materials such as titanium alloys for which the cutting toolpossibilities limit the speed). In this way, HSMspindle is an extremely critical bearing application. It ishighlighted by the $\mathrm{dm} . \mathrm{N}$ criterion (product of bearing mean diameter,in mm, and shaft speed, in rpm) that can reach 3000000 for HSM spindles; versus less than 500000 for classical bearing applications.

It can also be mentioned that, contrary to most of rotating machines, a large variety of force spectra is applied to a milling spindle during its lifetime. Indeed, many machining operations are carried out, with different tools (with different teeth number $Z$ ) and various cutting conditions (spindle speed, width of cut, ...). It is illustrated in Fig. 1 where two different cutting force spectra are presented. The first one corresponds to a contouring operation with a width of cut of $25 \%$ of the tool diameter, a spindle speed of $24000 \mathrm{rpm}$ and a two teeth tool. The force spectrum is composed of harmonics of the tooth passing frequency, given byj.Z.fr, where $f r$ is the shaft speed and $j$ the harmonic order [1]. The second example is a slot machining, thus the width of cut is the tool diameter; the spindle speed is $24000 \mathrm{rpm}$ and tool has four teeth. The force spectrum is only composed of a few harmonics of the tooth passing frequency. Moreover, the high spindle speeds can lead to cutting dynamic issues. Due to compliance of the tool or the workpiece, an instability, called chatter, may occur during the machining; if inadequate cutting conditions are used [1]. It conducts to severe vibrations that can damage the tool, the spindle or the workpiece.Lastly, cutter breakage may occur, leading to severe loads until the machine is stopped and the tool changed. To sum up, a large variety of force spectra will progressively damage the bearing along the spindle lifetime.

\section{Fig. 1. Examples of cutting forces}

In this context, bearing damage is the first cause of spindle failure, which appears to be the weak link of aeronautical HSM machines-tools. It can generally be observed in industry that the Mean Time To Failure (MTTF) is random and shorter than what isstated usually by the spindles manufacturers, due to the lifelong significant loads mentioned above [2]. Besides, spindles are taken off only for corrective maintenance, whereas condition-based maintenance could reduce repair costs. Even if it is possible to detect a spalling onset, there is a need for a reliable end-of-life criterion, in order to precisely monitor the condition of such spindle bearings and then to replace spindles at the very last moment. The paper 
focusses on the monitoring of defects that are uniformly distributed around the ring circumference.Even if prognosis could be an interesting perspective, it is not dealt in the paper.

In literature, two main kinds of bearing defects are considered: localized and extended defects [3]. Bearings failure of traditional rotating machines generally consists in a localized pit or spall on the inner or outer ring or on a rolling element, which locally spreads with time. The aim of the bearing condition monitoring is to detect the onset of localized defects as soon as possible. It can be monitored by two sorts of methods based on acceleration measurement: global criteria and spectral analysis. Global criteria like $\mathrm{V}_{\mathrm{RMS}}$ (Root Mean Square of vibration Velocity) or Crest Factor are easy to implement and do not depend on operating conditions [4]. When calculated on wide-band frequency signal, the reliability can be limited by masking effect. Indeed,the measures also include signals from other machine-tool components and their power in signal might hide the desired information concerning the spindle bearing condition. The Kurtosis characterizes the statistical distribution of signal in time domain. It is relevant to detect precocious defects in low-speed machines, but it is also sensitive to the noise. In order to enhance the sensitivity of these criteria (Crest Factor and Kurtosis), Dron et al. [5] have set up a spectral subtraction technique by separating the useful signal from the corrupting noise in certain frequency bands.

For more accuracy in the diagnosis, spectral analyses are used. Out-of-balance contribution at the shaft frequency $f r$ is common in rotor bearing assembly system, since various sources contribute to unbalanced rotation of the rotor. The spectral analysesmainly rely on the fact that, for example, each time a ball meets a localized defect on the innerrace; a cyclo-stationary impactoccurs. Consequently,a specific bearing-induced frequency appears in the spectrum of the vibration signal. The primary bearing-induced frequency,corresponding to a localized fault on each of the bearing elements, can be calculated from classical analyticalexpressions and bearing geometry: BPFO (Ball Pass Frequency of the Outer race), BPFI (Ball Pass Frequency of the Inner race), FTF (Fundamental Train Frequency) and BSF (Ball Spin Frequency) [6,7].

Resonance frequencies can then be excited by the sharp impacts of the primary bearing-induced frequency, leading to amplitude modulation sidebandsspaced at the bearing-induced frequencyin the vicinity to the resonance frequency. Note that resonance frequencies of the spindle shaft can be obtained by tap test or by simulations [8,9]. A number of researches have been carried out for demodulating the responses,isolating and identifying the specific causes of the spectral contributions.In the case of high speed rotors, some methods can be compromised by the fact that the impulse responses generated by the sharp impacts in the bearings may have a comparable length to the separation between the impacts [3]. The methods of envelope analysis such as Hilbert-Huang transform [10], of Wavelet decomposition [11] or of Auto Regressive Moving Average method applied in frequency domain [12] have conducted to good results concerning spindle applications. ConcerningBrinelling, where a race is indented by the rolling elements giving a permanent plastic 
deformation, the entry and exit events are not so sharp, and the range of frequencies excited not so wide but it can generally be detected by envelope analysis [3].

Few researches concern extended or distributed defects. However, with time, a localized defect can locally spread and becomes an extended defect, affecting a large portion of the raceway circumference.Then, signals can present an amplitude modulated white noise, which can be considered assecond-order cyclo-stationary signal [3]. Then, cyclo-stationary approaches mightbe used.

Besides, global bearing defects are generally considered as some distributed defects [13]. Indeed, manufacturing defects in form and finish of rolling elements and raceway surfaces induce other vibrations. The secondary effects of the surfaces waviness, off-sized balls and non-linearity of the ballrace contact stiffness were modeled as cyclo-stationaritiesand conducted to the analytical expressions of the secondary bearing-induced vibration frequencies $[6,7,11,12]$. Considering the raceway waviness for example, even if the defect is distributed on the whole groove circumference, cyclo-stationary approaches are still compatible due to the periodic nature of the defect. Interesting results were obtained concerning high speed spindle issues [7,12].

Lastly, if a raceway roughness of poor quality is considered, the defect is uniformly distributed all around the ringgroove circumference. Stochastic signals would be measured during the ball rolling process. Thus, the cyclo-stationary approaches cannot be conducted. The distributed defects investigated in this paper are of this nature. It was also observed in [14]. In that case, the above mentioned methods are not suitable. Rare works deal with noise monitoring or modeling for bearing condition issues.Some global criteria, such as $\mathrm{V}_{\mathrm{RMS}}$, could be used to quantify and monitor the noise but they might be unreliable due to strong masking effect. On a two-stage gearbox, Antoni [15] observed an increase of high frequency noise, but it wasdue to bearing localized defects. In the example, the primary bearing-induced frequency was in the low-frequency part of the spectra and masked by gear-mesh harmonics and sidebands. The author revealed the bearing-induced frequency by computing cyclic coherences and, besides, he suggested that a Gaussian noise can be included in the model.Behzad et al. [16] published a very interesting approach in relation to the present topic of this paper. The proposed model assumes a stochastic source of vibration excitation, which resultsfrom metallic contact between bearing elements during rolling. It is inspired from Feldmann [17] who introduced a microscale surface roughness model, based on an elastic rough contact models with a pseudo-random distribution of the contact points, which produces a broadband random noise during the ball rolling process.Behzad et al. [16] then simulate the effect of an extended bearing fault. When a defect grows in the bearing, the roughness of the contacting surfaces increases locally and stochastic excitation becomes stronger in the defective area. It was found that the vibration level increase at the defective area is a good indicator of bearing extended faults. The stochastic model leads to a Gaussian 
distribution of the time series of the ball-race contact force. It differs from the model introduced in this paper that relies on a Gaussian distribution of vibrations in the frequency domain.

This paper presents the evolution of a typical case of distributed defects occurring on HSM spindles. The vibration signals are discussed in relation to the different steps of bearing failure. It is shown that this kind of defects results in a noise component in the vibration signals. These signals are characterized in the frequency domain; it is demonstrated that the distribution of the frequency spectrum follows a Gaussian law whatever the state of the bearings. A new criterion, called SBN (Spindle Bearing Noise), is then proposed for the monitoring of spindles bearings distributed defects. A monitoring system and a specific protocol have been established and implemented in aerospace industry, in order to evaluate the criterion on spindles under realistic conditions. Finally, the relevancy of SBN is studied by comparison with four classical criteria, depending on three required conditions for bearing monitoring.

\section{Observation of a typicalHSM spindle bearing failure}

In this section, a typical evolution of bearing failure as it can be encountered on HSM spindle is presented. The front and rear bearing vibrations were measured at four successive stages, along the spindle lifetime, on the machine-tool of an aircraft manufacturer. Measures were obtained during idle rotations at $17500 \mathrm{rpm}$, after a warm-up cycle. This24 $000 \mathrm{rpm}-70 \mathrm{~kW}$ Fischer MFW2310 spindle is identified as the spindle $\mathrm{N}^{\circ} 2$ in section 4 , where the bearing geometry,arrangement and characteristic frequencies, the instrumentation, the specificmonitoring device and the experimental procedure are completely detailed.

During the UsinAEproject (French FUI), a preliminary study had been carried out with the spindle manufacturer on thisspindle. Based on the experience ofthe project partners, which notably consists in approximately 250 bearing failure analyses after spindle disassembly,the authors are confident when mentioning that the spindle bearing failure presented in this section is a typical one.

Fig. 2.a. Unused bearing

Fig. 2.b. Defect onset on the whole circumference of raceway

Fig. 2.c. Ceramic ball cleavage and extended defect on the groove

Fig. 2.d. End-of-life of the bearing

Fig. 2.Failure mode of spindle bearings and corresponding vibrations.

Fig. 2a presents the front bearing vibrationspectrum measured with the unused bearing, after the running-in and before the first machining. A similar spectrum was obtained at rear bearing. A minor contribution at the outer race fault frequency BPFO can be noticed at $3296 \mathrm{~Hz}$ (eq. 7). Indeed, 
concerning hybrid ball bearing, it appears even for unused bearing. A small contribution at shaft speed $f r(261.7 \mathrm{~Hz})$ is also common.Besides, the roughness of the outer-race groove of a similar unused bearing has been measured at $\mathrm{Ra}=0,06 \mu \mathrm{m}$ (with an AliconaInfinite Focus optical device, based on focus-variation).

The front bearing signature presented on Fig. $2 b$ has been established after four month of production. On the frequency spectrum, the contribution at BPFO frequency has increased significantly. An extensive analysis of the vibrations measured during the machining operations, revealed that a tool breakage occurred the day before [2]. A tool breakage lasts about half a second and generates very significant forces. Then, the broken edge(s) lead(s) to cutting difficulties and strong vibrations. The 100C6 steel raceways are indented by the ceramic balls, giving permanent plastic deformations. Due to the cutting force harmonics (cf. Fig. 1) and the large number of balls, Brinell marks rapidly appear all along the circumference of the raceway.The pictureof the front bearing was taken after the final disassembly but complementary vibration signatures have shown that the front bearing condition have evolved few since Fig. $2 b$ signature.It presentsa light strip on the whole circumference of the bearing outer raceway and a few larger indentations, revealing the plastic deformations. This light strip can be observed on most of (not too damaged) bearing after disassembly of the HSM spindle, uniformly distributed on the inner and outer race. Many peaks are observed on the spectrum in Fig. 2b. Some of these peaks are identified as primary induced frequencies, for example the contribution related to ballto-outer race speed at $3296 \mathrm{~Hz}$, as well as the shaft frequency at $292 \mathrm{~Hz}$. Secondary bearing frequencies also appears in the spectrum, like the side-band frequencies spaced at FTF in the vicinity of BPFO.Moreover, a low level noise can be observed on a broadband beyond $2500 \mathrm{~Hz}$. It is probably due to the degraded ball-race contact on the light strip. Besides, the ceramic balls can present some fine scratches.

Fig. $2 \mathrm{c}$ and $2 \mathrm{~d}$ present the vibration spectra of the rear bearing respectively three weeks before the spindle end-of-life and a few hours before. An increase of the noise level and an expansion to the whole frequency band can be noticed. It is explained by the raceways roughness that hasprogressively worsened(Fig. 2d). Ra roughness values of $5.7 \mu \mathrm{m}$ and $1.6 \mu \mathrm{m}$ were measured on respectively the inner and outer rings. Actually, after the above mentioned tool breakage, the machining has continued during several minutes with damaged tool, generating strong vibrations at the rear bearing essentially. As a consequence, not only the raceways were damaged but also the ceramic balls, on which small cleavages occurred (Fig. 2c and 2d). Ceramic chippings and the damaged balls then damage the whole raceway circumference by ploughing effect. Chippings also provoke new ball cleavages. Since the raceway groove curvature radius is close from the ball radius on this kind of bearing, all groove width is damaged. Small ceramic inclusions of less than half millimeter diameter have been found into the raceways.Damages have also obstructed some of the thin holes dedicated to the bearing lubrication. The spindle disassembly also revealed that the cage of this bearing was broken in two; 12 balls presented small damages, 4 balls some severe damages and 9 balls were destroyed or fragmented. 
In this way, a uniformly distributed defect appeared on the rear bearing raceways and generated a noise component in the vibration signal, due to the worsening of the ball-raceway contact during the rolling process.

\section{Characterization of the noise produced by bearing condition}

Consequently to the observation of an increasing noise in relation to the bearing condition, the purpose of this section is tocharacterize this noise and design of a new criterion for the monitoring of the uniformly distributed defect.

\subsection{Decomposition in spectral components}

Let us consider a vibration signal in frequency domain $X(k)$ issued from an HSM spindle, constituted of $K$ discrete components. The signal $X(k)$ can be considered as the sum of several main components:

$$
X(k)=F_{c}(k)+F_{S}(k)+F_{b}(k)+R_{b}(k)+F_{e}(k)+F_{n}(k)+R_{m}(k)
$$

The contribution of the machining process, at the harmonics of the tooth passing frequency and eventually a chatter frequency (close from the tool eigenfrequency), is noted $F_{c}(k)[1] . F_{s}(k)$ representscontribution at the shaft frequency that is notably due to the out-of-balance, and itsharmonics[7]. $F_{b}(k)$ refers to the contributions of the primary (BPFO, BPFI, BSF, FTF) and secondary bearing-induced vibration frequencies[6,7,12].It differs from the noise component $R_{b}(k)$ due to uniformly distributed defect on the bearing, as observed in the previous section. In modern spindles, the motor is integrated into the spindle and controlled by PWM (Pulse Width Modulation).The pulse frequency of the spindle drive PWM (parameter \$MD1100 in Siemens 611D drive) can produceelectromagnetic interferences $F_{e}(k)$ in the vibration signal at the pulse frequency harmonics [18]. Other mechanical components of the spindle or of the machine-tool (tool clamping system, rotary manifolds, rotor or structure eigenfrequencies, etc.) also contribute at specific frequencies $F_{n}(k)$ in the vibration signal[8]. Lastly, the measuring and quantification noise $R_{m}(k)$ due to the acquisition chain and the signal digital processing, can be assumed as constant.

The contributions $F_{c}(k), F_{s}(k), F_{b}(k), F_{e}(k)$ and $F_{n}(k)$ are deterministic components,modeled by a given set of frequencies in the vibration signal. On the one side, they are assumed to be the components of highest magnitude in the frequency spectrum. On the other side, this set of frequencies has a negligiblecontribution in the distribution of spectral components, due to their low number compared to the $K$ discrete components of the signal,if a sufficient frequency resolution is considered.It can be 
deduced that the distribution of the spectral components of $X(k)$ is dominated by the stochastic components $R_{b}(k)$ and $R_{m}(k)$, since the deterministic components are negligible. Then, as the measuring noise $R_{m}(k)$ is assumed constant, it can be concluded that the distribution of the spectral componentsisrelevant in order tocharacterize the noise produced by the bearing condition $R_{b}(k)$, especially if the spectral component are expressed in $\mathrm{dB}$.

\subsection{Characterization of the spectrum distribution}

As concluded in the previous section, the evolution of the frequency components distribution is of first interest.Fig. 3 shows the frequency spectrum (expressed in $\mathrm{dB}$ ) and the distribution of its components for two states of the rear bearing discussed in section 2: unused and damaged (cf. Fig. 2a and 2d). $X(k)$ is composed of $K=64000$ components since time signal were recorded at a sample frequency of $f_{e c h}=$ $25.6 \mathrm{kHz}$ during $\Delta T_{a c q}=5 \mathrm{~s}$.

Fig. 3.Frequency spectra and their distributions for unused and damaged bearings.

The distribution of $X(k)$ spectral components changedin relation to the bearing condition. The magnitude of the $X(k)$ components increased. It is observed thatthe distributions seem to follow a Gaussian law, which will be studied in this section. Besides, it is verified that the deterministic components, with the highest magnitude, represent a negligible portion of the distribution, whatever the bearing condition. Lastly, it can also be concluded from Fig. 3 that the measuring noise $R_{m}(k)$ is negligible, since it assumed constant contrary to the bearing condition $R_{b}(k)$ that evolves with time. Consequently, the bearing condition $R_{b}(k)$ is the only significant contribution in the distribution of $X(k)$ spectral components.

In order to demonstrate whether the distribution follows a Gaussian law, the correlation test of Pearson is used [19].

$$
\mu_{P}=\frac{\sum_{p=1}^{K}(X(k)-\bar{X})(Y(k)-\bar{Y})}{\sqrt{\sum_{p=1}^{K}(X(k)-\bar{X})} \sqrt{\sum_{p=1}^{K}(Y(k)-\bar{Y})}}
$$

where $\bar{X}$ is the mean of $X(k), Y(k)$ the mathematic law in relation to which the correlation is searched, here a Gaussian law; and $\bar{Y}$ the mean of this law. The value $\mu_{p}$ of the test is equal to $O$ when there is not any correlation between experimental values and the mathematic law and it is equal to $l$ when the correlation is exact. 
Bearings $n^{\circ} 1,3$ and 5 refer to the rear bearings while $n^{\circ} 2,4$ and 6 refer to the front bearings of respectively the two spindles presented in section 4 as well as another spindle of the same type. For each bearing, 100 vibration measures were recorded. At the end of this test campaign, bearings $n^{\circ} 1$ and 3 were out of service (some of their balls were destroyed). The other bearings presented distributed defects on the raceways but were still working.

Fig. 4.Correlation test of Pearson for six HSM spindle bearings

The Pearson test was performed for the 100 measures of the 6 monitored bearing. Results are the $\mu_{\mathrm{p}}$ values presented in Fig. 4. Whatever the bearing and its condition, the correlation test of Pearson is between 0.92 and 0.99 , proving that $X(k)$ distribution follows a Gaussian law. Thus, as the other signal contributions are negligible in the spectrum distribution, it can be concluded that the noise produced by the bearing condition $R_{b}(k)$ follows a Gaussian distribution all along the spindle life.

\subsection{Spindle Bearing Noise}

From the previous results, a criterion which could describe the increasing noise due the uniformly distributed defects is researched. Since $X(k)$ follows a Gaussian distribution, the mean of the distribution can be considered.Besides, it seems to increase with the noise generated by the bearing. Indeed, differences have been noticed between mean values of distributions respectively calculated for unused and worn-out bearings (cf. Fig. 3). In order to monitor the bearing condition until its end-oflife, it is necessary to define a unique threshold linked to the criterion. So, at the spindle end-of-life, the criterion must reach the same value from one spindle to another. The authors have investigated several criteria based on the evolution of the Gaussian mean. The most adequate form of the criterion is proposedhere:

$$
S B N=\frac{S B N_{0}}{\bar{X}}
$$

where $\mathrm{SBN}_{0}$ is the mean of the $X(k)$ Gaussian distribution evaluated when the bearing is unused.

Relevancy of the Spindle Bearing Noise (SBN) criterion is studied in the following sections. It is tested on several spindles, in industrial conditions, and compared to the current best practices issued from literature. The protocol and the instrumentation of spindles are presented in the next paragraph. 


\section{Experimental setup}

\subsection{Spindle and bearings}

Three Fischer MFW2310 spindles (24000 rpm, $70 \mathrm{~kW}$ ) have been studied and monitored.The bearing arrangement can be found in Fig. 5. It is equipped withSNFA VEX70 bearings at the front and VEX60 at the rear.Tab. 1 presents the bearing geometric characteristics and the bearing fault frequencies that have been deduced [7]. The spindles have been instrumented with four accelerometers that measure vibrations in both radial directions at the front and at the rear bearings (Fig. 5).

Fig. 5.Drawing of the spindle.

\begin{tabular}{|c|c|c|c|c|c|c|c|c|}
\hline & $\begin{array}{c}\text { Mean } \\
\text { diameter } D_{m} \\
(\mathrm{~mm})\end{array}$ & $\begin{array}{c}\text { Ball } \\
\operatorname{diameter} D_{b}(\mathrm{~mm})\end{array}$ & $\begin{array}{c}\text { Number } \\
\text { of } \\
\text { balls } N_{b}\end{array}$ & $\begin{array}{c}\text { Contact } \\
\text { angle } \alpha \\
\left({ }^{\circ}\right)\end{array}$ & $\begin{array}{c}\text { BPFO } \\
(\mathrm{Hz})\end{array}$ & $\begin{array}{c}\text { BPFI } \\
(\mathrm{Hz})\end{array}$ & $\begin{array}{c}\text { BSF } \\
(\mathrm{Hz})\end{array}$ & $\begin{array}{c}\text { FTF } \\
(\mathrm{Hz})\end{array}$ \\
\hline $\begin{array}{c}\text { SNFA } \\
\text { VEX60 }\end{array}$ & 77.50 & 7.94 & 25 & 25.0 & $11.34 * f_{r}$ & $13.66 * f_{r}$ & $4.84 * f_{r}$ & $0.45 * f_{r}$ \\
\hline $\begin{array}{c}\text { SNFA } \\
\text { VEX70 }\end{array}$ & 90.00 & 9.52 & 25 & 25.0 & $11.30 * f_{r}$ & $13.70 * f_{r}$ & $4.68 * f_{r}$ & $0.45^{*} f_{r}$ \\
\hline
\end{tabular}

Tab. 1. Bearings characteristics.

The spindles were mounted on Forest-Line 5-axes machine-tools in two different plants of Airbus and Dassault Aviation that essentially manufacture aluminum alloy structural parts. The three spindles were monitored daily,during approximately 3 months, from its mounting in the machine-tool when unused up to their end-of-life. Note that for spindle $n^{\circ} 1$, measurements were not yet automatic. So, only a few measures were carried out. Whereas about two hundred daily measures were recorded for spindles $n^{\circ} 2$ and 3 . Each one definitely failed because of one of their bearings, as presented in Tab. 2 .

\begin{tabular}{|c|c|}
\hline Spindle & Cause of failure \\
\hline $\mathrm{n}^{\circ} 1$ & Front bearing \\
\hline $\mathrm{n}^{\circ} 2$ & Rear bearing \\
\hline $\mathrm{n}^{\circ} 3$ & Rear bearing \\
\hline
\end{tabular}

Tab. 2. Cause of failure for each monitored spindle. 


\subsection{Specific monitoring system}

A specific acquisition system was developed and implemented on industrial machine-tools so as to collect real life vibration data and to evaluate the relevancy of bearing condition monitoring criteria. It enables daily vibration measurements on spindles of machine-tools in production without restraint for the industrial production of workpieces. As mentioned above, each spindle contains four accelerometers, in two orthogonal radial directions at the front and rear bearings. The integration of accelerometers into the spindle is also useful in order to avoid disturbances of surrounding environment. Moreover, it allows a good reproducibility because sensors are permanently mounted and are close from the bearings.

A specific monitoring system, called STORMIbox (Spindle Tool for Online Recording and Monitoring in Industry), was developed to perform the in-process monitoring of spindles. IBIS Accelerometers signals are recorded via a National Instrument 9234 acquisition card with a sampling frequency of $25.6 \mathrm{kHz}$. The system was also connected to the Computerized Numerical Command (CNC) Siemens 840D and records other information related to the spindle (power, bearing and stator temperatures), the process and the machining context (Fig. 6). The system is permanently installed in the machine and enables a continuous and automatic data recording for the whole lifetime of spindles.

Fig. 6.Specific monitoring system

A specific protocol was set up in order to avoid possible disturbances in the bearing vibrationsignature, such as variations of machining forces, temperature, spindle speed, tool unbalance, dynamic behaviour of the structure, etc. During a machine-tool production day, it always exists short periods without cutting. One of them was chosen. Measurements are automatically carried out daily during idle rotation, just after a spindle warm-up program (spindle is at the same temperature), with the same balanced dummy tool and at the same machine-tool position.

A specific program dedicated to the measurements is automatically launched by the CNC once a day, just after a spindle warm-up. It brings into play several spindle speeds that are commonly used while machining. Thanks to the link with the $\mathrm{CNC}$, the program can be detected by the monitoring system that launches the acquisition. In this way, the four accelerometers signals are automatically recorded daily at $25.6 \mathrm{kHz}$ and during five seconds of idle rotations at 15000, 17500, 19500, 21100 and 23750 rpm. 


\section{Evaluation of SBN}

$S B N$, the new criterion that has been proposed, is compared with four other criteria commonly used for bearing condition monitoring: $A_{R M S} A_{R M S}$, Kurtosis, Crest Factor and $S B_{B P F O}$.

$A_{R M S}$ is a global time domain criterion. It is the Root Mean Square (RMS) of the acceleration. It is defined by:

$$
A_{R M S}=\sqrt{\frac{1}{N} \sum_{n=0}^{N-1}(x(n)-\bar{x})^{2}}
$$

with $\bar{x}$ the mean of the time series $x(n)$. Kurtosis is a statistical parameter allowing the analysis of the distribution of the vibratory magnitudes contained in a time domain signal. It corresponds to the moment of fourth order divided the square of the standard deviation:

$$
\text { Kurtosis }=\frac{\frac{1}{N} \sum_{i=0}^{N-1}(x(n)-\bar{x})^{4}}{\left[\left(\frac{1}{N}\right) \sum_{i=0}^{N-1}(x(n)-\bar{x})^{2}\right]^{2}}
$$

The Crest Factor is another time domain criterion consisting in the ratio between maximum magnitude of the time signal and $A_{R M S}$.

$$
\text { Crest Factor }=\frac{\max (x(n))}{A_{R M S}}
$$

Lastly, a simple frequency domain criterion is considered, named $S B_{B P F O}$. It evaluates the RMS value of a thin frequency band in the vicinity of the Ball Pass Frequency of the Outer race of bearings (BPFO). This characteristic fault frequency can be theoretically calculated from bearing geometry:

$$
B P F O_{t h}=\frac{N_{b}}{2}\left(1-\frac{D_{b}}{D_{m}} \cos \propto\right) * f_{r}
$$

with $N_{b}$ the number of balls of the bearings, $D_{b}$ the ball diameter $(\mathrm{mm}), D_{m}$ the mean diameter of the bearing $(\mathrm{mm}), \alpha$ the contact angle of the bearing $\left(^{\circ}\right)$ and $f_{r}$ the rotational speed $(\mathrm{Hz})$. For the considered VEX bearing, $B P F O_{t h}$ is equal approximately to 11.3 times the rotating speed (in $\mathrm{Hz}$ ). The frequency band is defined in order to get free from the possible variations of the BPFO frequency. The variations can be due to rotation speed and thermal effects; from one spindle to another, they also can be due to 
assembly bearing preload or bearing manufacturing tolerances. Thus, the following frequency band on which $S B_{B P F O}$ is calculated has been retained (Tab. 2):

\begin{tabular}{|c|c|c|c|c|}
\cline { 2 - 3 } \multicolumn{1}{c|}{} & \multicolumn{2}{|c|}{ Theoretical frequency } & Lower cut-off & Upper cut-off \\
frequency & frequency \\
\cline { 2 - 3 } & Front bearing & Rear bearing & $11.19 * f_{r}$ & $11.68 * f_{r}$ \\
\hline
\end{tabular}

Tab. 2.Frequency band of $\mathrm{SB}_{\mathrm{BPFO}}$

The comparison ofSBN with these criteria is based on three conditions $\mathrm{C} 1, \mathrm{C} 2$ and $\mathrm{C} 3$ which guarantee that a criterion is efficient for the monitoring of the bearing condition, until the end-of-life:

- C1: limited dispersion of the values over time;

- C2: continuous increase of the curve in relation to spindle condition;

- C3: identical final value at the end-of-life of spindles.

The aim of condition $\mathrm{C} 1$ is to limit interpretation errors between consecutive measures. This condition is evaluated by the following procedure. Criterion values obtained from each daily measure form a time series that is high-pass filtered in order to eliminate the global evolution and isolate the noise (Fig. 6). The period corresponding to the cut-off frequency was chosen as 10 days. Then the standard deviation that is the indicator of $\mathrm{C} 1$ condition is calculated. It increases with dispersions.

The aim of condition $\mathrm{C} 2$ is to monitor the continuous evolution of the uniformly distributed defect studied in the paperbearing. This condition is characterised by the low-pass filtered time series of a criterion. As the noise is eliminated, the global evolution is revealed (Fig. 7).

\section{Fig. 7.Filtering of criterion time series}

Condition C3 concerns the end-of-life.In order to set a monitoring threshold, the criterion value at the end-of-life must be identical whatever the spindle. Deviations of the end-of-life values is evaluated by the ratio range to mean of the criterion final values.

SBN and the four comparative criteria have been evaluated for each spindle vibration signature that have been collected concerning the three studied spindle. Fig. 8 and fig. 9 show the evolution of the five criteria applied to vibrations of rear bearing respectively for spindle $\mathrm{n}^{\circ} 2$ and 3 , at $15000 \mathrm{rpm}$. Rear bearing failure occurred on the spindles. For the two graphs, the left ordinate axis corresponds to $A_{R M S}$, Crest Factor and $S B_{B P F O}\left(\right.$ in $\left.\mathrm{m} / \mathrm{s}^{2}\right)$; the right ordinate axis corresponds to Kurtosis and $S B N($ expressed in the International System Units). 
Fig. 8.Comparisonof $\mathrm{SBN}$ with other criteria for spindle $\mathbf{n}^{\circ} 2$

Fig. 9. Comparison of $\mathrm{SBN}$ with other criteria for spindle $\mathrm{n}^{\circ} 3$

Criteria are then discussed depending on the three conditions $\mathrm{C} 1, \mathrm{C} 2$ and $\mathrm{C} 3$.

- Condition $\mathrm{C} 1$

Tab. 3presents the dispersion of the five criteria, through the standard deviation. Kurtosis presents the lowest dispersion. $S B N, S B_{B P F O}$ and $A_{R M S}$ are also interesting.

\begin{tabular}{|c|c|c|c|c|c|}
\hline & $A_{R M S}$ & $\begin{array}{c}\text { Crest } \\
\text { Factor }\end{array}$ & $S B_{B P F O}$ & Kurtosis & $S B N$ \\
\hline $\mathrm{C} 1$ & $5.10^{-5}$ & $3.10^{-4}$ & $7.10^{-5}$ & $6.10^{-6}$ & $5.10^{-5}$ \\
\hline $\mathrm{C} 3$ & $17 \%$ & $50 \%$ & $14 \%$ & $18 \%$ & $4 \%$ \\
\hline
\end{tabular}

Tab. 3. Results of conditions $\mathrm{C} 1$ and $\mathrm{C3}$

\section{- Condition C2}

This condition evaluates the global evolution of the criteria over time, after low-pass filtering of time series. Except for $A_{R M S}$ and $S B_{B P F O}$, curves are globally rising over time, for the two spindles. Kurtosis values vary few (from 2.3 to 3.1). Moreover, in the case of spindle ${ }^{\circ} 3$, Kurtosis keeps a constant value for the three months before the definite failure. This kind of evolution does not match with the aim of anticipating the end-of-life of bearings. Conversely $S B N$ is regularly rising from the initial time to the end of each spindle. Therefore $S B N$ provides the best results concerning condition C2.

\section{- Condition C3}

Tab. 3 presents the value of condition C3 for the five criteria, which evaluate the criteria values deviation at the end-of-life. $S B N$ has the lowest deviation between its final values. This result is supported by the SBN evolutions concerning the three spindles that are presented in Fig (computed from vibrations measured for a spindle speed of 23750rpm). Moreover, it can be noticed that the correct bearing (front or rear) is identified for a given failure.In the case of spindle $n^{\circ} 1$, the breakage of the front bearing is the cause of breakdown; for spindles $n^{\circ} 2$ and 3 , the cause is the breakage of the rear bearing (Tab. 1). The $S B N$ final values concerning the incriminated bearings are close to 2.5 . The results are very promising in order to define a monitoring threshold for spindles condition based maintenance.

Fig. 10.a. SBN for spindle $n^{\circ} 1-$ failure of the front bearing Fig. 10.b. SBN for spindle $n^{\circ} 2$ - failure of the rear bearing Fig. 10.c. SBN for spindle $n^{\circ} 3$ - failure of the rear bearing 


\section{Fig. 10.SBN for spindles $n^{\circ} 0,1$ and 2}

Based on the conclusions of the three evaluation conditions, it can be concluded that $S B N$ is a relevant criterion for the monitoring of HSM spindle bearings, in presence of uniformly distributed defect. Its values are regularly rising all along the bearings life. The dispersions are limited and a threshold has been identified close to 2.5(for this spindle), through the different cases that have been studied. As the spindle sample is too small to be considered as a statistical sample, these results should be consolidated with further experiments.

\section{Conclusion}

In this paper, typical failure mode of HSM spindle bearings was studied from the perspective of the observations of their uniformly distributed defects and the relative vibration signals. It is shown that this kind of defects leads to a noise component growing in the vibration frequency spectrum. The correlation test of Pearson allows the authors demonstrating that the distribution of the frequency spectrum follows a Gaussian law whatever the failure level of the bearings. Then, a new criterion, called SBN (Spindle Bearing Noise), was proposed for the characterisation of such distributed defects. Specific data acquisition system and protocol were defined in order to finely monitor the evolution of the criterion on spindles working in industry. $S B N$ was compared with four other criteria commonly used for bearing condition monitoring. They were analysed through three expected conditions (low dispersion, continuous increase, unique threshold). Results showed that $S B N$ is the most relevant criterion to monitor distributed defects and to predict the end-of-life of spindle bearings.

\section{Acknowledgments}

The authors thank all partners of the research program "UsinAE". It brought together aircraft manufacturers, machine-tools and spindles manufacturers, research laboratories and technology transfer companies. It was funded by the French government.

\section{References}

[1] Y. Altintas, E. Budak, "Analytical Prediction of Stability Lobes in Milling”, Annals of the CIRP, Vol. 44/1, pp. 357-362, 1995. 
[2] C. de Castelbajac, "Advanced monitoring and improvement of HSM process", Doctoral Thesis of the University of Nantes (France), Aug. 2012.

[3] R. B. Randall and J. Antoni, "Rolling element bearing diagnostics - A tutorial," Mech. Syst. and Signal Process., vol. 25, no. 2, pp. 485-520, Feb. 2011.

[4] C. Pachaud, R. Savetat, and C. Fray, "Crest Factor and Kurtosis contributions to identify defects inducing periodical impulsive forces,” Mech. Syst. and Signal Process., vol. 11, pp. 903-916, 1997.

[5] J. P. Dron, F. Bolaers, and L. Rasolofondraibe, "Improvement of the sensitivity of the scalar indicators (crest factor, kurtosis) using a de-noising method by spectral subtraction: application to the detection of defects in ball bearings," J. of Sound and Vib., vol. 270, no. 1-2, pp. 61-73, Feb. 2004.

[6] F.P. Wardle, "Vibration forces produced by waviness of the rolling surfaces of thrust loaded ball bearings, Part 2, experimental validation", Proceedings of the Institute of Mechanical Engineers, Part C: J. of Mech. Eng. Sci., vol. 202, pp. 313-319, 1988.

[7] N. Lynagh, H. Rahnejat, M. Ebrahimi, R. Aini, "Bearing induced vibration in precision high speed routing spindles”, Int. J. of Mach., Tools and Manufact., vol. 40, pp. 561-577, 2000.

[8] Y. Cao, Y. Altintas, "Modeling of spindle-bearing and machine tool systems for virtual simulation of milling operations”, Int. J. of Mach., Tools and Manufact., vol. 47, pp. 1342-1350, 2007.

[9] D. Noël, M. Ritou, S. Le Loch, B. Furet, "Bearings influence on the dynamic behaviour of HSM spindle", Proceedings of the ASME 11th Biennial Conference \& on Engineering Systems Design and Analysis, Nantes, France, 2012.

[10] L. S. Law, J. H. Kim, W. Y.H. Liew, S. K. Lee, “An approach based on wavelet packet decomposition and Hilbert-Huang transform (WPD-HHT) for spindle bearings condition monitoring”, Mech. Syst. and Signal Process., vol. 33, pp. 197-211, 2012.

[11] S. Vafaei, H. Rahnejat, "Indicated repeatable runout with wavelet decomposition(IRR-WD) for effective determinationof bearing-induced vibration", J. of Sound and Vib., vol. 260, pp. 67-82, 2003. 
[12] S. Vafaei, H. Rahnejat, and R. Aini, "Vibration monitoring of high speed spindles using spectral analysis techniques,” Int. J. of Mach. Tools and Manuf., vol. 42, no. 11, pp. 1223-1234, 2002.

[13] N. Tandon, A. Choudhury, Review, Tribol. Int., vol. 32, pp. 469-480, 1999.

[14] T. Hoshi, "Damage Monitoring of Ball Bearing," CIRP Annals - Manuf. Technol., vol. 55, no. 1, pp. 427-430, Jan. 2006.

[15] J. Antoni, "Cyclic spectral analysis of rolling-element bearing signals: Facts and fictions", J. of Sound and Vib., vol. 304, pp. 497-529, 2007.

[16] M. Behzad, A. R. Bastami, D. MBA, “A New Model for Estimating Vibrations Generated in the Defective Rolling Element Bearings”, ASME J. of Vib. andAcoust., vol. 133, nº, 2011.

[17] J. Feldmann, "Point distributed static load of a rough elastic contact can cause broadband vibrations during rolling”, Mech. Syst. and Signal Process., vol. 16, pp. 285-302, 2002.

[18] SIEMENS, "SIMODRIVE 611 digital/SINUMERIK 840D/810D - Drive Functions Function Manual".

[19] J. L. Rodgers, W. A. Nicewander, "Thirteen ways to look at the correlation coefficient”, Am Stat., vol. 42, no. 1, pp. 59-66, 1988. 